\title{
BREATHING LIFE BACK INTO THE STORIES: CREATING THE CIRCLE OF INDIGENOUS LANGUAGES WEBSITE
}

\author{
Charlotte Ross 1 \\ University of Victoria \\ Joan Greyeyes \\ Onowa McIvor \\ University of Victoria
}

\begin{abstract}
This paper describes an innovative project undertaken to create a website to share historical recordings of the nēhiyaw (Cree), Nahkawe, and Michif languages of Saskatchewan. Each author played a role in the delivery of a graduate program that took place simultaneously alongside the creation of the Circle of Indigenous Languages (COIL) website. This paper explores the importance of Indigenous networking and a collective consciousness towards Indigenous language revitalization as neither project would have happened without the spark and interconnection of the other. Weaving together our language experiences, we highlight the strength of aligned synergies. This paper also addresses critical issues pertaining to cultural continuity for Indigenous Peoples by embracing technology. Therefore, the greatest impact of the COIL project was to koskopita (reawaken) the stories from inaccessible formats in private collections. The project of digitization, categorization, and website creation provided access to old stories, and therefore "whole language," now shared in the public domain. Our journey with technology and the experience gained can be used by other language communities to support Indigenous language documentation.
\end{abstract}

Keywords: digitization, archiving, website creation, adult language learning, Indigenous language revitalization, nēhiyaw, Nahkawe, Michif

Citation: Ross, C., Greyeyes, J., \& McIvor, O. (2021). Breathing life back into the stories: Creating the circle of Indigenous languages website. WINHEC: International Journal of Indigenous Education Scholarship, 16(1), 302-333.

http://dx.doi.org/10.18357/wi1202120290. Special Issue on Indigenous Language Revitalization: Innovation, Reflection and Future Directions, Guest Co-Editors Drs. Onowa McIvor and Kari A. B. Chew.

${ }^{1}$ Charlotte Ross, University of Victoria, charlotteross@uvic.ca 


\section{Introduction}

As nēhiyaw educators, we share stories of our journey in Indigenous language revitalization (ILR) drawing from the COIL website as a focal point for our aspirations and collective consciousness. Using storywork (Archibald, 2008) as theory and method, we present our stories and work carried out in this paper as intertwined and woven together based on our shared commitment to language revitalization. The paper includes both the coming together of the authors as a collective, as well as the efforts of the COIL project team which concurrently transpired. Utilizing retrospective analysis (Hermes et al., 2012), the authors reflect on the process that the COIL project team used to digitize, categorize, and create a website for Indigenous language story compilation. The impetus to write the paper stems from the importance of the COIL project's contribution to the field of adult language learning and, more specifically, the need for access to first-language speakers' recordings. This paper also covers issues pertaining to access to cultural continuity for Indigenous Peoples. It explores the importance of Indigenous networking and a collective consciousness towards ILR. This paper adds to the discourse about how and why accessibility to Indigenous languages matters to Indigenous people and why it is important for the world to retain these languages and knowledges. 


\section{Our Stories}

\section{Charlotte}

Charlotte Ross is a nīhithaw iskwīw (Woodland Cree woman) raised in northern Saskatchewan. She is a second-year doctoral student focused on ILR at the University of Victoria. She grew up surrounded by nīhithawīwin (the Woodland Cree language) and learned how to read and write in nēhiyawēwin (Plains Cree language) while in university using the Standard Roman Orthography from late Dr. Freda Ahenakew. In 2016, she was hired to be an Indigenous Language Consultant supporting the students and instructors in the University of Victoria's Masters in Indigenous Language Revitalization (MILR) program hosted in Saskatchewan, where she first met Onowa. Shortly after, she also began working with Joan on the COIL project, which included digitization, categorization, and website creation. Both projects were completed in 2018 when the website was launched and the MILR students completed their graduate program.

\section{Joan}

Joan Greyeyes is a nēhiyaw iskwēw (Plains Cree woman) from Saskatoon, Saskatchewan. She completed a graduate degree in Educational Administration from the University of Saskatchewan and has significant experience as a senior executive, contributing valuable knowledge working with corporate, government, and Indigenous relations at the postsecondary level. Joan's commitment to Indigenous education and expertise in negotiating for First Nations within institutions and provincial and federal governments secured the delivery of the University of Victoria MILR program in Saskatchewan in 2016 as well as funding for the COIL project including digitization, categorization, and website creation. Joan 
met Onowa through an international Indigenous studies conference and had an established working relationship with Charlotte as an Indigenous Languages Consultant over many years. Joan's role was central to both the MILR program delivery in Saskatchewan and the COIL project funding, development, and actualization as a functioning resource.

\section{Onowa}

Onowa McIvor is maskékow-ininiw (Swampy Cree) and Scottish-Canadian. Her family is from kinosao sipi (Norway House) and Pimicikamak (Cross Lake) in northern Manitoba. She is a grateful visitor now in SENĆOFEN and Lkwungen speaking territories. Onowa is a lifelong learner of her mother's nēhinawēwin (Cree language), and an Associate Professor focused on ILR at the University of Victoria. She teaches and supervises graduate students focused on ILR and co-leads the NETOLNEW Research Partnership, a project working to understand and enhance Indigenous adults' contributions to reviving Indigenous languages in Canada. A part of this national research project includes building a virtual space for Indigenous language communities to share their learning and teaching activities. This project, entitled NETOLNEW Indigenous Language Learning Atlas (nilla.ca), currently under development, together with teaching and supervising in the MILR program brought Onowa together with Joan and Charlotte across their shared passions for language revitalization, building proficiency, building resources for adult learners, and the power of networking for growing and sustaining the work of ILR. 


\section{Our Language Connects Us}

We are three $\mathrm{Cree}^{2}$ women who share a commitment to strengthening, building, and learning our nēhiyawēwin (Plains Y-dialect), nēhinawēwin (Swampy N-dialect) and nīhithawīwin, (Woodland TH-dialect), Cree language, representing three different dialects. The team approach we embraced is similar to other scholars such as McGregor et al. (2016); McIvor et al (2017); Rosborough and Rorick (2017); and Thomas et al. (2020). Our lives, as with the scholars mentioned, have intertwined and connected through post-secondary education as we believe that education is key to the revitalization of our Indigenous languages. Our paths came together through an initiative with the University of Saskatchewan's Office of First Nation \& Métis Relations (OFNMR) and the University of Victoria aimed at offering an ILR graduate program. ${ }^{3}$ Our shared belief in revitalizing Indigenous languages is what brought us together initially to māmawī-atoskātamāk (to work together) on delivering the MILR program. As the COIL project was beginning to take shape at the same time, there was cross fertilization about the critical role of Indigenous language recordings to language learning. Faculty shared the latest research and issues in ILR with the students through course delivery and discussions, sharing their experiences as language teachers. As the MILR program progressed and the COIL website was being developed, language teachers in the MILR program (and beyond) commonly shared their frustrations at the lack of Indigenous language audio resources. They expressed challenges in identifying short language clips to

\footnotetext{
${ }^{2}$ We use the more generic anglicized term Cree when referring across all authors and dialects of which we are three.

${ }^{3}$ For more information on this initiative and connection see the following: https://news.usask.ca/articles/general/2016/indigenous-language-holds-the-key-to-culturalpreservation.php https://www.cbc.ca/news/canada/saskatoon/victoria-indigenous-language-program-coming-universitysaskatchewan-1.3674175
} 
support their student's learning outcomes. The design of the website included categorization and sub-indexing incorporating the feedback we received from Indigenous language teachers to suit their pedagogical needs.

Through our collective energies, an online Indigenous language resource to support language learners was created. Joan recollected the intricate historical background, while Charlotte contributed consultative support to both the categorization and website development. Onowa, as an international ILR researcher with some expertise with building web-resources and networking, provided a broader perspective for how the website contributed to and supported adult language learning. The website provided critical resources for adult language learners with limited access to first-language speakers, which is critical to creating speakers.

Following the completion of the digitization, categorization, and creation of the website, we utilized retrospective analysis to reflect on our experiences (Hermes et al., 2012). Our reflections on what we contributed and learned from the COIL project are key to understanding how the project began and evolved. Hawaiian scholar Manulani Meyer (2014) reminds us that language work requires good energy, good intentions, and a good heart, to have good healing as an intended outcome. We realized in retrospect that we followed Meyer's philosophy, as the common goal for the COIL project was based on revitalizing Indigenous languages for the healing of our people. 


\section{Storywork}

We write from a theoretical lens of storywork, relationships, and decolonization using narrative inquiry to highlight the importance of a relational approach (Smith, 2012). As Indigenous authors, we want to tell our own stories, write our own versions, in our own ways, and for our own purposes (Archibald et al., 2019; Smith, 2012). We share the story of our experience in reaching out to others for their expertise in storying a mentorship relationship. We reflect on how we worked with individuals to digitize their historical language recordings, making them publicly accessible, with permission, on a website. It was important, at the outset, to establish respectful relationships with all our partners in this project for it to be completed ethically and in a good way.

Wilson (2008) applies an Indigenous methodological frame to investigate the experience of being an Indigenous scholar within the university system. If Indigenous ways of knowing were to be narrowed through one particular lens, he asserts, that lens would be relationality and relational accountability. This concept is carried out in our writing as we reflect how we supported the MILR graduate program while simultaneously working on the COIL project. Both of these initiatives were carried out based on being accountable to all our relations. We needed to ensure that we made careful choices for all aspects of the initiatives and how we would present them as we were accountable for our intentions. From the beginning of both initiatives, ceremonial Elders and traditional knowledge keepers guided the process to ensure that we followed protocols inherent to the territory. 
Kovach (2009) uses storytelling as the centre of transmission of Indigenous epistemologies, knowledge, and teachings, writing about Indigenous methodologies from a nēhiyaw perspective. Our project was based on following the principles of story work with informal visits with individuals who had historical recordings they wanted to digitize and share on a public website, with the intention of "reawakening" the stories.

The seven theoretical Indigenous storywork principles as articulated by Archibald (2008), and exemplified by Archibald and Parent (2019), are respect, responsibility, reverence, reciprocity, holism, interrelatedness, and synergy. Reflecting on the inclusion and engagement of traditional knowledge keepers and the community in both the MILR program and the COIL project, the seven principles of Indigenous storywork guided our work. The individuals involved in the MILR program, and the COIL project embraced these principles as they worked together toward a common goal. Early in the MILR program and the COIL project, we shared the intentions respectfully with the ceremonial Elders and knowledge keepers first to demonstrate reverence and responsibility for the nature of the work. Once ceremony was carried out, we met with the MILR cohort and the COIL project team to share the intentions and discuss how ILR was being supported by their involvement (holism and interrelatedness). We had regular contact with MILR program cohort and faculty along with the COIL project team to ensure synergy for the projects.

This process has been referred to as language ideological clarification (Kroskrity, 2009), which has been identified as a significant factor in the success of language renewal activities. Language ideological clarification was critical to the success of the MILR program and the 
COIL project to have clear communication clarifying the purpose and intention. At regular intervals, the MILR program and COIL project team clarified intentions and timelines to ensure we were of the same understanding. Joan's role was crucial as she personified the background and history to the COIL project as well as the motivation to actualize the MILR program offering in Saskatchewan.

\section{Literature Review}

In keeping with our storywork methodology approach to this paper, we have interwoven aspects of the COIL website creation within our review of relevant literature on Indigenous languages, documentation, and online resource creation.

Indigenous languages face many challenges, but technology can be used in language learning to contribute to revival and revitalization (Galla, 2016; Herman et al., 2020; Smith et al., 2018). There is considerable planning required for engaging technology in ILR depending on what the technology is intended to support (Hermes et al., 2016). To help communities navigate their readiness for technology, a technacy framework for language revitalization (TFLR) is strongly recommended (Galla, 2016). The framework includes consideration of critical factors that can inform the level of readiness for technology. The questions to ask focus on the community's language status or background preparation in 1) linguistic and cultural, 2) social, 3) technological, 4) environmental, and 5) economic areas (Galla, 2016). With the use of technology to help archive, document, preserve, revitalize, and maintain the voices of Indigenous people, it is an act of gifting future generations with priceless 
knowledge and wisdom while contributing to the success of Indigenous community resurgence (Galla, 2016; Ka'ai, 2017; Tukker, 2017; Wemigwans, 2018).

Embracing technology to support ILR is not new for some global Indigenous Peoples. Two examples are the Māori and the Hawai'ian peoples whose language revitalization best practices are often held up for their innovation and as models for Indigenous languages to recreate. It is important to recognize that both language groups are singular in focus, which is a significant difference from the North American context. Given that, the following examples are noteworthy. Ka'ai (2017) offers insight into Māori language revitalization and technology through the Te Whare Matihiko o te Reo, which is a funded research project. Critical to the Māori language strategy was the establishment of the Te Ipukarea, the National Māori Language Institute, in 2008. A key component of the Māori Language Institute's mandate was to develop and advance a digital strategy for the creation, delivery, and assessment of Māori language curricula in addition to the collection and dissemination of Māori knowledge across domains. In addition, the development of speech resources for the Māori language using a Text-To-Speech (TTS) synthesis will be one of the first TTS resource for the language (James et al., 2020). Text-To-Speech has potential for applications like ereaders and talking books for learners working to improve proficiency. Developers working on TTS synthesis understand the work is critical especially when the availability of firstlanguage speakers is rapidly diminishing across all Indigenous language groups (Bontogon et al., 2018; Littell et al., 2018). 
Regarding the Hawaiian efforts, it has taken about five decades of committed advocacy to resuscitate the Hawaiian language to be spoken as a first language by two full generations (Galla, 2018b). With support from Apple and Microsoft, the Hawaiian language is supported across most platforms to strengthen Hawaiian language revitalization. Not only has access to digital technology increased the domains of language use, but it has also provided access to culturally relevant and authentic materials from an Indigenous worldview without the limitations of physical geography (Galla, 2019; Herman et al., 2020). Technology allows languages to be experienced multimodally in broad domains, while permitting access to language resources in homes, schools, offices, and on the land as language learning is enhanced by domain usage (Galla, 2016; Herman et al., 2020).

As technology is now a part of our daily life, the journey of language learning often includes the use of technology to access programs, dictionaries, websites, fonts, and apps to support learning (Herman et al., 2020; Hermes et al., 2016; Jim, 2016). In addition to attending language learning workshops and training, learners who become familiar with digital resources can support their language learning in this way, as repetition is a key factor in learning to speak a new language. Language advocates and scholars share rich and diverse forms of technology that assist with language learning, including but not limited to, the Hawaiian, Cherokee, Ojibwe, and Mohave language groups (Hermes et al., 2016). Additionally, the First Peoples' Cultural Council (2020a) created a helpful resource for all communities called Check before you Tech! aimed at assisting communities at assessing the quality of existing resources and with useful tips for topics to think about when planning digital projects. 
During the interpersonal restrictions created by the COVID-19 pandemic, organizations such as the First Peoples' Cultural Council (2020b) in British Columbia, Canada created an online resource to assist individuals with ideas on how to continue their language learning virtually and at home. As one part of this, online access to audio and video recordings of spoken languages can be a great comfort to the language learners to hear their ancestral languages. We are reminded of a teaching shared on the COIL website by nēhiyaw Elder Mary Lee that language has a spirit and an energy that is contained within the flame of life that supports and nourishes the listener, a belief shared by others as well (COIL, 2017; Herman et al., 2020).

In Indigenous language communities, resources to support language learners are often scarce. Through organizations and partnerships, free online digital tools for language learning using audio recordings have been created such as online language tutorials, animations, social media, games, and materials storage (Galla, 2018a; 2018b; Herman et al., 2020; Ka'ai, 2017; Smith et al., 2018). Language revitalization is viewed as a long-term commitment to building community capacity with the assistance of partnerships to create technology-based teaching resources (Galla, 2016; Herman et al., 2020; Little et al., 2015). Scholars and language advocates acknowledge there needs to be a directed effort to build technological capacity within Indigenous communities (Galla, 2018a; Hermes et al., 2016; Wemigwans, 2018). Resources produced through language documentation, revitalization, training, and analysis are invaluable resources for many Indigenous language communities (Fitzgerald, 2020). When creating resources for learners, the length and quality of audio or 
video recordings is critical to the pedagogical needs of learners. To create multimedia software for an 0jibwe language learning resource, the recordings that were one to three hours in length did not meet the need for shorter video clips (Hermes et al., 2012). This held true for the COIL project as we also needed to create shorter audio clips using detailed categorization and sub-indexing (COIL, 2017; Ross, 2020; Ross \& Greyeyes, 2019; Ross \& Greyeyes, 2021).

\section{Using Technology to Preserve Cultural Knowledge}

Scholars and cultural advocates refer to Indigenous knowledge that can be shared in an online format as "introductory" in nature and that will not bring harm to others if shared (Four Directions Teachings, 2006; Restoule, 2019; Saskatchewan Indian Cultural Centre, 2009; Wemigwans, 2018). It was through a similar understanding that the ceremonial Elders and traditional knowledge keepers in the COIL project ensured the nature of the content was introductory, would not bring harm to others, and was therefore appropriate for sharing in a public forum.

The COIL website was being created as Wemigwans (2018) was composing her book entitled A Digital Bundle in which she strongly advocates for the use of technology in the preservation and sharing of Indigenous knowledge. As authors, and among the COIL project team, we shared similar beliefs regarding technology and Indigenous language preservation and sharing. The Four Directions Teachings website features traditional stories from Elders and traditional teachers while addressing the importance of being able to publicly access traditional knowledge respectfully. Saskatchewan nēhiyaw Elder Mary Lee, who is also 
featured on the COIL website, shares these values also from a nēhiyaw perspective. The Four Directions Teachings website features a strong case study on how Indigenous communities can create online learning opportunities while respecting Indigenous knowledge, protocols, and paradigms.

Striking similarities exist between the COIL project and a Canadian Broadcasting Corporation ( $\mathrm{CBC}$ ) North project undertaken to inventory, digitize, and catalogue audio recordings of first-language speakers (Faille-Lefrançois, 2017; Shapiro, 2020). In the CBC project, a North Slavey language broadcaster expressed the historical and cultural importance of preserving, digitizing, and cataloguing their stories as many of them were told by Elders who are no longer alive (Tukker, 2017). We share their point of view, as many of the story tellers on the COIL website have passed on and were traditional knowledge keepers.

\section{Recordings as Pedagogy}

Like the COIL project, Bontogon et al. (2018) discuss using technology to support nēhiyawēwin (Cree language) learning in higher education where the main community involvement was the contribution of audio recordings. While an adult learner can learn morphology and structure of the nēhiyawēwin (Cree language) through a university course, it is the oral practice and intonations most easily accessed and practised through recordings that move learners to higher levels of usage and retaining the language (Belcourt, 2021). 
As the COIL project involved considerable effort to create a digital archive of recordings, the outcome could have been to focus on documenting Indigenous languages and studying the language. Documentary linguistics is a linguistic specialization concerned with producing high quality recordings that are then translated, transcribed, and annotated for further research by linguists specializing in the field of studying the language (Austin \& Sallabank, 2017). However, through the COIL website, we are taking the important next step of activating the recordings to support Indigenous language reclamation, revitalization, and pedagogy as modeled by other scholars and activists before us (Cushman, 2013; Fitzgerald, 2020; Johnson, 2017; Little et al., 2015; Tukker, 2017).

\section{Website Creation}

\section{Project Goals}

The COIL digitization, categorization, and website project focused on several key actions. The overall goal was to preserve the historical recordings for posterity and to provide teaching resources on a publicly accessible website. The first step then was to collect, ${ }^{4}$ sort, and review the recordings by consulting with ceremonial Elders and knowledge keepers regarding the suitability of content for the website. Materials deemed not appropriate for a public audience including mainstream recordings or that were of a personal nature were returned to those who donated the recordings. Second, the recordings that were suitable for a public audience were digitized, and a digital copy of the recording was returned with the original recording to the individual or organization. Third, once the recordings were

\footnotetext{
${ }^{4}$ More information in the following sections on how the recordings were collected.
} 
digitized, the audio files underwent a detailed categorization and sub-indexing process by a team of first-language speakers. Fourth, our online mentoring program provided access to language mentors for learners interested in learning more about the Indigenous language recordings posted on the website. Fifth, the website provided space for individuals to directly upload recordings through the website. Sixth, we established an on-site recording studio in partnership with the University of Saskatchewan's Department of Indigenous Studies, separately funded, to facilitate on-site interviews and record stories with Indigenous speakers.

\section{Background to Website Creation}

The vision to create a digital learning resource involved individuals committed to Indigenous language and oral history preservation. Together they held the foresight for future generations and efforts that would require creativity to preserve both oral history and Indigenous language. As a lifelong advocate for Indigenous languages reflecting nēhiyaw oral history, the digitization of historical recordings and creating of an Indigenous languages website were centrally part of the dream and vision for late Tyrone W. Tootoosis. Over several years, recorded stories were collected by late Tyrone W. Tootoosis in his work with traditional ceremonial Elders and storytellers across Saskatchewan. He was an avid oral historian who was self-taught and raised in a family of orators inheriting his late father's collection of stories. In addition, Dr. Winona Wheeler (Indigenous Studies, University of Saskatchewan), a professionally trained oral historian, had a collection of stories by distinguished knowledge keepers on topics pertaining to Indigenous history. The collections were privately stored and made available through relationships built between key 
individuals involved in the COIL project who shared a mutual commitment to oral history preservation and ILR.

Based on meetings with the COIL project team and the storyholders, a top priority was to preserve and digitize historical recordings that were on reel-to-reel, cassette, VHS, microcassette, and beta tapes. In addition to preserving Indigenous language materials, our goal was to share the language recordings on a publicly accessible website. However, this idea presented a challenge as there was not an existing website that could support the language recordings to adequately meet our vision. This led to the idea to include designing and building a website to host the Indigenous language recordings.

\section{Circle of Indigenous Languages (COIL) Website}

The COIL website is a digital learning centre and database created from the audio and video files donated by individuals and organizations. A project team for the website developed the website in conjunction with Elders and traditional knowledge keepers to preserve and share Indigenous languages while adhering to cultural protocols. The foundational and planning work was based in Saskatchewan (Canada) while the website designers were in eastern Canada. Establishing strong working relationships built on foundations of trust and respect were integral to the project as our COIL project team meetings were held virtually. Funding was secured to design and build the website in addition to the cataloguing and categorization from sources such as the National Indian Brotherhood Trust Fund, Canadian Internet Registration Authority, and the Aboriginal Language Initiative. One of the website partners was the Saskatchewan Indigenous Languages Advisory Committee (SILAC) along with 
individual Saskatchewan Indigenous language speakers who contributed to the categorization and sub-indexing of the recordings.

The name of the website, Circle of Indigenous Languages, reflects the philosophy of our traditional knowledge keepers and the nēhiyaw worldview, which is holistic in nature, cyclical, and forward moving. We carried this out by consulting with Elders and traditional knowledge keepers while following traditional protocols. Elder Mary Lee shares from a nēhiyaw worldview on where language originates from. She shared this knowledge in an interview conducted in nēhiyawēwin (the Cree language) which is posted on the COIL website along with a translation to English (COIL, 2017). Part of the website design included creating a visual image that would reflect the nēhiyaw understanding of how and where language originates from. The artist worked closely with the Elder to provide the culturally appropriate images for the origin of nēhiyawēwin and the meaning behind each of the symbols and colors in the artwork on the website.

\section{Receiving Recordings}

In order to properly track the recordings, a subject index catalogue format was provided by Dr. Wheeler as it included details critical for an oral history collection. A catalogue entry was created for each of the recordings. Upon receiving the first collection, from the Tootoosis and Wheeler collections, a sampling of the reel-to-reel, beta and microcassettes tapes were selected for digitizing to determine the content. The second collection received was from a Saskatchewan Aboriginal broadcasting organization. This collection consisted of a sampling of the historical collection of reel-to-reel tapes in the Indigenous languages that they had 
created for broadcasting programming. The third collection was received from an Indigenous journalist as he had heard via "the moccasin telegraph" 5 that the project was underway and donated a portion of his private collection. The fourth collection was received from a Saskatchewan First Nation organization who had also heard about the project and wanted to digitize a sample of their historical collection. Other recordings were shared by individuals and their families as they also continued to hear about the project from others. The digitization process involved accessing services locally in addition to the website design team. Once digitized, the audio files were shared with the COIL project team through OneDrive or Google Drive in addition to a hard copy in CD or DVD format.

\section{Categorizing with Knowledgeable Speakers}

Once the categories were established by the COIL project team, the recordings were categorized by first-language speakers. The categorizers had previous experience working with language recordings, using technology, and were knowledgeable about traditional protocol and spirituality. The categorizers were provided access to a laptop with training to listen to recordings using two different software programs to keep track of timing within a recording. This training included the use of Microsoft Word and Excel to document the categorization of each recording. The categorizers were already proficient speakers who shared that listening to the recordings strengthened their own language knowledge. The process generated many conversations among the categorizers as they would come together to discuss the recordings they had reviewed. During this process, they shared that the

\footnotetext{
5 The moccasin telegraph is an informal oral means of communication usually between relatives, friends and
} associates. 
recordings triggered positive memories, and they would reminisce about the individuals who were recorded as they were well known traditional knowledge keepers and storytellers. Their language spirits were nourished by hearing the language used in recording oral histories.

\section{Assessing Quality and Suitability-Ethical Considerations}

From the beginning, the project team was committed to honour the teachings and languages that were shared by those who donated recordings. Traditional protocol and ceremony were followed with the ceremonial Elders and knowledge keepers to honour the stories of those who had passed on to the spirit world. The storytellers shared their teachings for future generations to learn the language and the teachings, as both are intertwined and inseparable. Traditional protocol with respect to the recordings was followed throughout this process. The importance of adhering to ethics in working with Indigenous people, communities, and language materials is critical as shared by Indigenous scholars (Absolon, 2011; Kovach, 2009; Smith, 2012; Wilson, 2008). The project adhered to the ethics and responsibilities inherent to working with Indigenous language recordings by following traditional nēhiyaw and Nahkawe protocol guided by ceremonial Elders and knowledge keepers (SICC, 2009). Part of these protocols is that they cannot be publicly shared or explained here; rather they must be witnessed or can be discussed in certain circumstances orally, but it is important to document here that they occurred and were a foundational component of this project and story. 


\section{Connection to Wider Landscape}

The shift over into the technological space for ILR work has been in some ways slow. Of course, this shift has begun to gain speed during the pandemic of 2020 and beyond. However, the long-term effects are yet to be known. Within that, the COIL project and particularly the undertaking of collecting, digitizing, and categorizing Indigenous language recordings is part of a larger set of undertakings across Canada and further afar. Here we will name just a few. The National Research Council (NRC) of Canada runs the Canadian Indigenous languages technology project, which was granted \$6M in 2017. Littell et al. (2018) explain the various foci of this work that include a category of computer aided language learning, which contains courses embedded with recordings organized as resources for learners. Other projects they support are other forms of digitization, as explained on their website (NRC, 2020), such as segmenting and indexing audio recordings, as well as support for online tutoring software (with audio). An additional entity entitled Indigitization is a collaboration between Indigenous groups in $\mathrm{BC}$ and academic partners, created to support the digitization and systemic archival of precious materials (https://www.indigitization.ca). A key difference between many of these projects and the COIL website is that they are either digital preservation for the sake of preserving or, in the case of some of the NRC projects, are documentation projects created for the purpose of creating resource products (such as short clips for audio dictionaries and other technologies). The COIL project, however, combines the archival digitization work of organizations like Indigitization with a pedagogical focus of creating specific curriculum resources, stories in "usable" chunks for K-12 teachers and adult learners. 
Another connection to the wider landscape and future of digital tools in ILR is the NILLA project (nilla.ca) currently underway through NETOLNEW: “One mind, one people" Indigenous language research grant. The online portal space would be a wider, broader space for the COIL website to be embedded within a context of language learners or teachers seeking connection across language revitalization efforts.

\section{Intended Outcomes}

There were many outcomes from the project. While some were planned, others were unintentional, yet everyone benefitted from being involved. We learned that connections and relationships are critical elements, and consistent communication is foundational to efficient work and building trust. Success for the project meant receiving recordings, cataloguing, and digitizing them as a first step. Success was gauged by properly categorizing and sub-indexing the stories. The goal for the project was designing and building a website to host the categorized audio recordings for learners and to facilitate additional language learning and sharing.

We received feedback from nēhiyawēwin (Cree language) teachers that were using the website audio clips to share the language and support students' learning outcomes. The website was utilized to support several Mentor Apprentice Program teams over a two-year period to access whole language learning as well as listening to the traditional teachings that the Elders in the recordings shared. At each stage of the website development, we shared the progress with the Elders, knowledge keepers, and language teachers to incorporate their feedback into the next stage of development. 
With the categorization process, we learned that technology training is important at the forefront. It was critical to have individuals who were first-language speakers in the Indigenous languages and were comfortable working with technology. We learned that subindexing was an invaluable resource for learners and teachers searching for specific content that was in a usable format. We understood that dialect differences in listener knowledge were important to affirm and acknowledge throughout the project. As the recordings were often of an unknown content, we worked on matching the categorizers with the same dialect of the speaker on the recording to accurately reflect the stories on the file.

\section{Unintended Outcomes}

There were several unintended outcomes throughout the project. The Elders, knowledge keepers, and categorizers (all of whom were first-language speakers) experienced a deeper understanding of their own language and teachings, which was enriched by the opportunity to hear the recordings. The audio recordings in Cree are primarily the recordings of speakers using a high level of fluency as they were elderly speakers and traditional knowledge keepers. The speakers shared that listening to the recordings strengthened their own language as they remembered old words that are not spoken often and felt supported to bring them back into use. The process of categorizing the language recordings created a rich resource for the first-language speakers to hear the language and be encouraged in their continued language use. Another unintentional outcome was that the recordings were used in senior level university nēhiyawēwin Cree language courses for students to practice their transcribing skills. 
Individual support and background information was provided for the categorizers to discuss any questions on the content of the recording. The categorizers also felt that they were learning about the speakers, their philosophies, and the teachings they were providing which was also an unplanned outcome. We learned that it was important to provide opportunities for first-language categorizers to work together, and not alone, to interpret a recording as the recorded speakers were often traditional knowledge keepers who had unique life histories and philosophies that grounded their stories within their life experience.

\section{Knowledge Dissemination}

The authors felt that it was important to share the process and outcome of the COIL project for several reasons. The dissemination provided an opportunity to share with others the experience of not only creating a website but also digitizing historical recordings that were then categorized and shared on the website. Presentations were shared at three international Indigenous language conferences on the development of the COIL website including the International Conference on Language Documentation and Conservation (ICLDC) conferences (Ross \& Greyeyes, 2019, 2021) and the International Indigenous Languages conference, HELISET TFE SḰÁL: Let the Languages Live (Greyeyes \& Ross, 2019). We were able to review the intention of the website with our audiences and determine if there were similar websites that existed for other language groups. Joan and Charlotte were invited to participate in a national Indigenous language roundtable discussion by invitation for Onowa's SSHRC Connections grant-funded roundtable in January 2019, with representatives from across Canada, focused on the creation of NILLA (mentioned above), an online portal for language communities and organizations to share their success stories 
and pedagogies with one another. And finally, a webinar was delivered through Maskwacis Cultural College on the background and development of the COIL website to an international audience with a mutual vested interest in the use of technology to preserve Indigenous languages (Ross, 2020).

\section{Conclusion}

In this paper, we shared the learning journey we have undertaken to digitize historical Indigenous language recordings, to catalogue and categorize these stories, and lastly, to create a publicly accessible website to share the recordings. This project has highlighted the importance of preserving and documenting historical recordings of the nēhiyaw, Nahkawe, and Michif languages in Saskatchewan. The authors and the COIL project team had the correct motives for success-good energy, good intentions, and a good heart-that we believe lead to healing the spirit of the language (Meyer, 2014).

We shared similar philosophical outlooks, values, and beliefs regarding the importance of oral history and ILR and the possibilities held in strengthening networks and digital resources as tools to support learning. We had key individuals who shared a vision and began researching how we could share the language as widely as possible. The yarn that connected community members, educators, and scholars was our commitment to revitalizing and strengthening our Indigenous languages using digital archiving and website creation to assist us in making the audio recordings more accessible to a wider audience. Throughout our work, we were guided and blessed by ceremonial Elders and traditional knowledge keepers who ensured that we followed traditional protocols as our languages are sacred. 
There is a need for a greater abundance of quality and accessible audio and video resources to support language learning, which the COIL project was designed to address. Writing about our journey together with interwoven projects was an act of honouring the many individuals involved, but particularly those who made the COIL website come to life and contributed their ideas, energy, and language into making it a reality. We valued being able to communicate in nēhiyawēwin (Cree language) by text or email as we collaborated on the writing of the paper as an affirmation to the tenacity and hope for our language despite years of colonization. We also share our story with the wider language revitalization community in hopes that our learning will assist others in their learning and resource development journeys. ahaw 


\section{About the Authors}

Charlotte Ross nitisithīkāson. Montreal Lake Cree Nation ohci nītha. I was raised with Cree as my first language. I am a doctoral student at the University of Victoria specializing in Indigenous Language Revitalization. My current research interests include the use of technology in language learning to support adult silent speakers in language revitalization.

Joan Greyeyes nisihkāson. Muskeg Lake Cree Nation kisiskācōwinihk nitakison. My recent work with the University of Saskatchewan centered around the preservation and revitalization of Indigenous languages. I created partnerships resulting in the delivery of the UVIC Masters of Indigenous Language Revitalization program in Saskatchewan along with the creation of the Circle of Indigenous Languages website.

Dr. Onowa McIvor nitisithīkāson. nītha maskēkow-ininiw (Swampy Cree) īkwa ScottishCanadian îkwa nēhithawīwin language learner and language warrior. I am a Professor of Indigenous Education at the University of Victoria. My current areas of research span Indigenous language revitalization, immersion and bilingual education, sociocultural language learning, additional language acquisition, and Indigenous health and well-being. 


\section{References}

Absolon, K. (2011). Kaandossiwin: How we come to know. Fernwood Press.

Archibald, J. (2008). Indigenous storywork: Educating the heart, mind, body, and spirit. UBC Press.

Archibald, J., Lee-Morgan, J., \& De Santolo, J. (2019). Decolonizing research: Indigenous storywork as methodology. ZED Books.

Archibald, J. \& Parent, A. (2019). Hands back, hands forward for indigenous storywork as methodology. In S. Windchief \& T. San Pedro (Eds.), Applying Indigenous research methods: Storying with peoples and communities (1st ed., pp. 3-20) Routledge. https://doi.org/10.4324/9781315169811-1

Austin, P. K. \& Sallabank, J. (2018). Language documentation and language revitalization: Some methodological considerations. In L. Hinton, L. Huss \& G. Roche (Eds.), The Routledge handbook of language revitalization (1st ed., pp. 207-215). Routledge. https://doi.org/10.4324/9781315561271-26

Belcourt, C. (2021, May 26). Tâhtimiwewin: Intonation and the musicality of sound in Anishinaabemowin and Nehiyawewin, and evolving strategies within Indigenous language revitalization efforts. [Webinar]. Indigenous Languages Institute.

Bontogon, M., Arppe, A., Antonsen, L., Thunder, D., \& Lachler, J. (2018). Intelligent computer assisted language learning (ICALL) for nêhiyawêwin: An in-depth user-experience evaluation. The Canadian Modern Language Review, 74(3), 337-362. https://doi.org/10.3138/cmlr.4054

Circle of Indigenous Languages (COIL). (2017). https://indigenouslanguage.ca/about/the-beginning-of-language

Cushman, E. (2013). Wampum, sequoyan, and story: Decolonizing the digital archive. College English, 76(2), 115-135.

Faille-Lefrançois, J. (2017, May 3). CBC North to preserve Indigenous history. Your CBC Radio Canada blog. https://cbc.radio-canada.ca/en/your-publicbroadcaster/blog/indigenous-history

First Peoples Cultural Council (2020a, July 20). Check before you tech! A guide for choosing language apps and software as part of your plan to reclaim revitalize and maintain your Indigenous language. https://fpcc.ca/wp-content/uploads/2020/09/FPCCCheck-Before-You-Tech.pdf 
First Peoples Cultural Council (2020b, July 16). Virtual \& at home language revitalization program ideas. https://fpcc.ca/wp-content/uploads/2020/10/FPCC-Virtual-AtHome-Language-Program-Ideas.pdf

Fitzgerald, C. M. (2020). Understanding language documentation and revitalization as a feedback loop. In S. Fafulas \& J. Benjamins (Eds.), Amazonian Spanish: Language contact and evolution (pp. 81-104). John Benjamins Publishing.

Four Directions Teachings (2006). http://www.fourdirectionsteachings.com/

Galla, C. (2016). Indigenous language revitalization, promotion, and education: Function of digital technology. Computer Assisted Language Learning, 29(7), 1137-1151, https://doi.org/10.1080/09588221.2016.1166137

Galla, C. (2018a). Technology training and praxis at the American Indian Language Development Institute: Computer applications for indigenous language communities. The Canadian Modern Language Review / La Revue Canadienne Des Langues Vivantes, 74(3), 388-433. https://www.muse.jhu.edu/article/702976

Galla, C. (2018b). Digital realities of indigenous language revitalization: A look at Hawaiian language technology in the modern world. Language \& Literacy, 20(3), 100-120. https://doi.org/10.20360/langandlit29412

Galla C. K. (2019). Materials development for Indigenous language learning and teaching: Pedagogy, praxis, and possibilities. In E. McKinley \& L. Smith (Eds.), Handbook of Indigenous Education (pp. 357-375). Springer. https://doi.org/10.1007/978-981$\underline{10-3899-0 \quad 12}$

Greyeyes, J. \& Ross, C. (2019, February 28-March 3). Circle of Indigenous languages [Poster presentation]. 6th International Conference on Language Documentation \& Conservation (ICLDC), Honolulu: HI, United States.

Herman, C., Daniels, B., Lewis, K., \& Koole, M. (2021). Awakening sleeping languages in Saskatchewan with culturally appropriate curricula and technology. In J. Traxler \& H. Crompton (Eds.), Critical mobile pedagogy: Cases of digital technologies and learners at the margins (pp. 123-135). Routledge.

Hermes, M., Bang, M., \& Marin, A. (2012). Designing indigenous language revitalization. Harvard Educational Review, 82(3), 381-402. https://doi.org/10.17763/haer.82.3.q8117w861241871j

Hermes, M., Cash Cash, P., Donaghy, K., Erb, J., \& Penfield, S. (2016). New domains for Indigenous language acquisition and use in the USA and Canada. In S. M. CoronelMolina \& T. L. McCarty, T. (Eds.), Indigenous language revitalization in the Americas. Routledge. https://doi.org/10.4324/9780203070673 
Hermes, M. \& King, K. A. (2013). Ojibwe language revitalization, multimedia technology, and family language learning. Language Learning \& Technology, 17(1), 125-144. http://dx.doi.org/10125/24513

James J., Shields I., Berriman R., Keegan P. J., \& Watson C. I. (2020). Developing resources for Te Reo Māori text to speech synthesis system. In P. Sojka, I. Kopeček, K. Pala, A. Horák (Eds.), Lecture notes in computer science, vol 12284. Text, speech, and dialogue (pp. 294-302). Springer.

Jim, J. (2016). WSÁNEĆ SEN: I am emerging. (Master's project, University of Victoria, Canada). https://dspace.library.uvic.ca//handle/1828/9849

Johnson, S. M. K. (2017). Syilx language house: How and why we are delivering 2,000 decolonizing hours in nsyilxcn. Canadian Modern Language Review, 73(4), 509537. https://doi.org/10.3138/cmlr.4040

Ka'ai, T. M. (2017). Te Whare Matihiko o Te Reo-digital tools for the revitalisation of te reo Māori. In H. Whaanga, T. T. Keegan, \& M. Apperley (Eds.), He Whare Hangarau Māori - Language, culture \& technology (pp. 29-34). Te Pua Wānanga ki te Ao (Faculty of Māori and Indigenous Studies) and Te Whare Wānanga o Waikato (University of Waikato).

Kovach, M. (2009). Indigenous methodologies: Characteristics, conversations, and contexts. University of Toronto Press.

Kroskrity, P. V. (2009). Language renewal as sites of language ideological struggle: The need for "ideological clarification." In J. Reyhner \& L. Lockard (Eds.). Indigenous language revitalization: Encouragement, guidance \& lessons learned (pp. 71-83). Northern Arizona University.

Littell, P., Kazantseva, A., Kuhn, R., Pine, A., Arppe, A., Cox, C., \& Junker, M. O. (2018). Indigenous language technologies in Canada: Assessment, challenges, and successes. Proceedings of the 27th International Conference on Computational Linguistics, Santa Fe, NM, United States, pp. 2620-2631. https://nrcpublications.canada.ca/eng/view/object/?id=fb46809a-7c06-403a-bd8d$\underline{\mathrm{f} 4437030 \mathrm{ef} 51}$

Little, C., Wysote, T., McClay, E., \& Coon, J. (2015). Language research and revitalization through a community-university partnership: The Mi'gmaq research partnership. Language Documentation \& Conservation, 9, 292-306. https://scholarspace.manoa.hawaii.edu/bitstream/handle/10125/24644/little.pdf

McGregor, C., McIvor, O., \& Rosborough, P. (2016). Indigenous communities and community-engaged research: Opportunities and challenges. Engaged Scholar Journal: Community-Engaged Research, Teaching and Learning, 2(1), 1-15. http://hdl.handle.net/10515/sy54j0bf3 
Meyer, M. (2008). Indigenous and authentic: Hawaiian epistemology and the triangulation of meaning. In N. K. Denzin, Y. S. Lincoln, \& L. T. Smith (Eds.), Handbook of critical and indigenous methodologies (pp. 217-232). SAGE Publications. https://doi.org// $10.4135 / 9781483385686$

National Research Council. (2020). Canadian Indigenous languages technology project. https://nrc.canada.ca/en/research-development/researchcollaboration/programs/canadian-indigenous-languages-technology-project

Restoule, J. P. (2019) Where Indigenous knowledge lives: Bringing Indigenous perspectives to online learning environments. In E. McKinley \& L. Smith (Eds.) Handbook of Indigenous education (pp. 1295-1317). Springer. https://doi.org/10.1007/978-981$\underline{10-1839-8 \quad 62-1}$

Rosborough, T. \& Rorick, C. L. (2017). Following in the footsteps of the wolf: Connecting scholarly minds to ancestors in indigenous language revitalization. AlterNative: An International Journal of Indigenous Peoples, 13(1), 11-17.

Ross, C. (2020, August 10). Circle of Indigenous languages website: Build it and they will come. Microlearning Maskwacis Cultural College. https://drive.google.com/file/d/1Vu7pH09VzMPfYmCqQLw5YYdPIz3i7bUk/view? usp= sharing

Ross, C. \& Greyeyes, J. (2019). Circle of Indigenous Languages. [Conference session]. HELISET TҒE SḰÁL: Let the Languages Live Conference, Victoria, BC, Canada.

Ross, C. \& Greyeyes, J. (2021, March 5-7). Circle of Indigenous languages [Conference presentation]. 7th International Conference on Language Documentation \& Conservation (ICLDC), virtual conference.

Saskatchewan Indian Cultural Centre. (2009). Cultural teachings: First Nations protocols and methodologies. Saskatchewan Indian Cultural Centre.

Shapiro, L. (2020, July 20). Sharing the stories at the heart of the culture. The CBC's Indigenous Languages Archive Project. https://drive.google.com/file/d/1KH50ubDEYQZRGxxVRrRpiEVcZwh oDE/view?usp=sharing

Smith, H. A., Giacon, J. \& McLean, B. (2018). A community development approach using free online tools for language revival in Australia. Journal of Multilingual and Multicultural Development, 39(6), 491-510. https://doi.org/10.1080/01434632.2017.1393429

Smith, L. T. (2012). Decolonizing methodologies: Research and Indigenous peoples (2nd ed.). Zed Books. 
Thomas, C., Benson, N., \& Lemon, M. (2020). (Be)coming together: Making kin through stories of language and literacy: Using métissage as a research praxis. Language \& Literacy, 22(1), 39-58. https://doi.org/10.20360/langandlit29515

Tukker, P. (2017, January 10). Voices from the past: CBC North to preserve historic Indigenous language programs. CBC News. https://www.cbc.ca/news/canada/north/cbc-indigenous-language-archive-project$\underline{1.3929833}$

Wemigwans, J. (2018). A digital bundle: Protecting and promoting Indigenous knowledge online. University of Regina Press.

Wilson, S. (2008). Research is ceremony: Indigenous research methods. Fernwood Publishing. 